\title{
Stromal Cell-Derived Factor-1-3'A Polymorphism Favors HIV-1 Infection in Mexican Women
}

\author{
Jesús Salvador Velarde-Félix ${ }^{\mathrm{a}-\mathrm{c}}$ Silvestre Guadalupe Cázarez-Salazar ${ }^{\mathrm{a}, \mathrm{b}}$

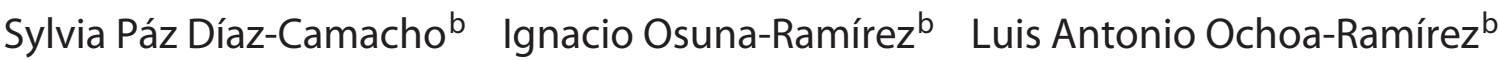 \\ Jorge Guillermo Sánchez-Zazuetac Martín Ramírez ${ }^{\mathrm{d}}$ \\ ${ }^{a}$ Centro de Medicina Genómica, Hospital General de Culiacán 'Dr. Bernardo J. Gastélum', Servicios de Salud de \\ Sinaloa, ${ }^{b}$ Maestría y Doctorado en Ciencias Biomédicas, Facultad de Ciencias Químico-Biológicas, Universidad \\ Autónoma de Sinaloa, ' Unidad Académica Escuela de Biología, Cuerpo Académico Inmunogenética y Evolución \\ UAS-CA-265, Universidad Autónoma de Sinaloa, and 'Laboratorio de Histocompatibilidad del Hospital General de \\ Culiacán ‘Dr. Bernardo J. Gastélum', Servicios de Salud de Sinaloa, Culiacán, Mexico
}

\section{Key Words}

Stromal cell-derived factor-1-3'A $\cdot$ HIV-1 $\cdot$ HIV/AIDS $\cdot$ CD4+ T lymphocytes · Viral load

\footnotetext{
Abstract

Objective: To evaluate the association of the stromal cellderived factor-1 (SDF1)-3'A polymorphism to HIV-1 infection, CD4+ T-lymphocyte counts, and viral load levels in a northwestern Mexican population. Methods: We investigated allele and genotype frequencies of the SDF1-3'A polymorphism in 634 mestizo individuals from Northwest Mexico (204 HIV-1 infected persons, 256 uninfected blood donors, and 174 uninfected female sex workers) by the PCRRFLP method and compared them using a $X^{2}$ test. We also searched for correlations between the polymorphism and CD4+ T lymphocyte and viral load counts. Results: No differences were observed in the frequencies of alleles and genotypes between patients and controls. However, in female pa-
}

tients we found a significantly increased prevalence of both the $A$ allele and GA heterozygous genotype compared to male patients, female blood donors, and female sex workers. Conclusion: Here we describe the association of the SDF13'A polymorphism with HIV-1 infection only in women, but not to CD4+ T-lymphocyte categories, viral load levels in patients with HIV-1/AIDS, or to exposure levels in female sex workers.

๑) 2016 S. Karger AG, Basel

\section{Introduction}

The World Health Organization (WHO) in its last report about the global HIV/AIDS epidemic estimated 2.1 million people were newly infected and 1.5 million people

J.S.V.-F. and S.G.C.-S. contributed equally to this work.

\section{KARGER 125}

(c) 2016 S. Karger AG, Basel

$0300-5526 / 16 / 0586-0357 \$ 39.50 / 0$

E-Mail karger@karger.com

www.karger.com/int
Jesús Salvador Velarde-Félix

Centro de Medicina Genómica

Hospital General de Culiacán 'Dr. Bernardo J. Gastélum'

Juan Aldama y Nayarit s/n. Col. Rosales, Culiacán, Sinaloa, CP 80230 (Mexico)

E-Mail jsvelfe@ hotmail.com 
had died [1]. Nevertheless, the United Nations and AIDS (UNAIDS) states that both the new infections and the number of AIDS deaths at the global level show a downward trend due, in part, to the implementation of prevention policies and also to access to better drugs [1].

In Mexico, over the past decade, the male-female ratio of HIV-1 cases has remained 4:1 [2]. In Mexican sex workers, the infection has a prevalence of $0.68 \%$ and they are 13.5 times more likely to get infected than other risk groups [2]; this population along with intravenous drug users who share needles, children born to HIV-1-positive mothers, and sexual partners of HIV-1-positive patients constitute an ideal model to study the factors involved in resistance to HIV-1 infection and AIDS [3]. Such resistance is multifactorial and explained by viral and host factors such as the human molecules that participate in viral entry, for example the chemokine receptors CCR5 and CXCR4, which serve as coreceptors for the R5 and X4 virus strains, respectively [4], while dual-tropic strains (R5X4) can also use CCR3 and CCR2b as minor HIV-1 coreceptors [5]. In the case of the X4 and R5X4 strains, the infection is prevented selectively in T-tropic HIV isolates by stromal cell-derived factor-1 (SDF-1) [6], which is a proinflammatory cytokine belonging to the CXC chemokine family [7], which possesses pleiotropic effects on chemotaxis, angiogenesis, immune response, and tumor metastasis [8].

The SDF-1 gene contains a single nucleotide polymorphism consisting of a G/A transition at position 801 in the $3^{\prime}$ untranslated region. This polymorphism, named SDF1-3'A or rs1801157, plays an important regulatory role in the production of SDF-1 [9] and has been the subject of extensive research for its alleged relationship with susceptibility/resistance to HIV-1 infection and progression to AIDS in different human populations.

For example, in the Thai population [10] the SDF1$3^{\prime} \mathrm{A}$ allele has been shown to be a protective factor against HIV-1 infection in female sex workers. Furthermore, it promotes slow progression to AIDS in long-term nonprogressing HIV-infected individuals from Paraná, Brazil [11] and New York, N.Y., USA [12]. However, other studies relate SDF1-3'A to an increased risk of HIV-1 infection and with a more rapid decline in CD4+ T cells and progression to AIDS [13-16]. Surprisingly, Liu and Zhu [17] in their meta-analysis (13 studies, 5,704 individuals among healthy people, exposed uninfected and HIV-1 patients) did not find a link between the SDF1-3'A genotype and susceptibility to HIV infection.

In Mexico, whose mestizo population (people of mixed European and Amerindian ancestry with a rep- resentativeness of $60 \%$ of total Mexican population) possesses a great and complex genetic variability, there is no information that contributes to clarify the participation of the SDF1-3'A allele in HIV-1/AIDS pathogenesis. Therefore, in this study, the distribution of the SDF1-3'A polymorphism was investigated in HIV-1 patients, healthy blood donors, and female sex workers, as well as its association with CD4+ T-lymphocyte counts and viral load levels as progression markers, in an attempt to elucidate its role in the Mexican mestizo population.

\section{Material and Methods}

\section{Study Population}

We studied a total of $204 \mathrm{HIV}-1$ infected patients (139 males, 65 females) from December 2011 to December 2013, 174 HIV-1 seronegative female sex workers, and $256 \mathrm{HIV}-1$ seronegative blood donors (160 males, 96 females). The clinical, transmission, and demographic data of the patients were obtained from the Center for HIV/AIDS Prevention and Treatment in Mazatlan and Culiacan, Sinaloa, Mexico (CAPASITS). CAPASITS are units that provide diagnosis, treatment, and health services for HIV-1 patients and are distributed around the country. There are three units in Sinaloa: Culiacan, Mazatlan, and Los Mochis.

Patients were classified according to current Centers for Disease Control and Prevention (CDC) criteria in three CD4+ Tlymphocyte categories, defined as: (1) $\geq 500$ cells/ml, (2) 200-499 cells $/ \mu$ l, and $(3)<200$ cells $/ \mu$ l. This parameter was measured using a FACSCalibur ${ }^{\mathrm{TM}}$ flow cytometer (Becton Dickinson). On the other hand, HIV-1 RNA levels in plasma were established by a semiautomated COBAS Amplicor HIV-1 monitor standard format (Roche Diagnostic Systems), which covers a dynamic range of 400-750,000 copies of HIV-1 RNA per $\mathrm{ml}$ of blood, allowing us to classify patients according to the amount of HIV-1 RNA as low-level or undetectable ( $<400$ copies/ml), middle (400-100,000 copies $/ \mathrm{ml})$, and high-level $(>100,000$ copies $/ \mathrm{ml})$. Both the categories and the levels were estimated according to the mean of all estimations of each patient. Additionally, 66\% of them were monitored for both CD4+ count and load viral levels since 2007 with three and two measurements per year, respectively. All patients were receiving antiretroviral therapy when the study was conducted, except for one 'elite controller' male patient. However, the therapy start date and the responses to treatment are unknown. The clinical and demographic data are presented in table 1.

The second group was represented by female sex workers, who were HIV-1-negative throughout the study period. They were interviewed at municipal medical services of Mazatlan and Culiacan. Condom use and work time were considered as variables to determine the exposure level to HIV-1. The first variable was measured as always or sporadic, and the second variable was measured in years. The product of these two variables allowed us to arbitrarily establish two exposure levels: low-level ( $\leq 1$ year working and with or without consistent condom use) and high-level ( $\geq 1$ year working and infrequent condom use). The blood bank of the Hospital 
Table 1. Epidemiology and clinical characteristics of HIV-infected patients in Sinaloa, Mexico

\begin{tabular}{|c|c|c|c|}
\hline Variables & Male $(\mathrm{n}=139)$ & Female $(n=65)$ & Total $(n=204)$ \\
\hline Age, years & $42 \pm 9.75(23-77)$ & $42 \pm 11.58(22-69)$ & $42 \pm 10.38(22-71)$ \\
\hline CD4+ T-cell count, cells/ $\mu \mathrm{l}$ & $467 \pm 253.47(112-1,496)$ & $545 \pm 282.47(165-1,495)$ & $492 \pm 264.87(86-1,496)$ \\
\hline \multicolumn{4}{|l|}{ Transmission path } \\
\hline IDU & $3(2.15)$ & $1(1.53)$ & $4(1.96)$ \\
\hline \multicolumn{4}{|l|}{ Sexual } \\
\hline HS & $57(41)$ & $2(3.08)$ & $59(28.92)$ \\
\hline HTS & $58(41.73)$ & $60(92.31)$ & $118(57.84)$ \\
\hline BS & $24(17.27)$ & $3(4.61)$ & $27(13.24)$ \\
\hline \multicolumn{4}{|l|}{ Clinical status } \\
\hline Other diseases & $81(58.27)$ & $22(33.84)$ & $103(50.49)$ \\
\hline HIV-1 only & $58(41.72)$ & $43(66.15)$ & $101(49.50)$ \\
\hline
\end{tabular}

Values represent the mean \pm standard deviation (range) or $\mathrm{n}(\%)$. IDU $=$ Intravenous drug users; HS = homosexual; HTS = heterosexual; BS = bisexual. Other diseases include, in descending order of frequency: wasting syndrome; candidiasis of bronchi, trachea, or lungs; intestinal cryptosporidiosis; pulmonary and extrapulmonary tuberculosis.

General de Culiacan provided the third group, the healthy blood donors. They were unrelated and without HIV-1 and hepatitis C or $\mathrm{B}$ viruses infection.

Participants were fully informed of the study protocol by the investigators prior to signing the written informed consent. The present study was approved by the Ethics Committee of the Escuela de Biología of Universidad Autónoma de Sinaloa and by the Ethics and Research Committee of Hospital General de Culiacan. Moreover, parents and grandparents of all participants were born in Sinaloa state, thus ensuring the ancestral component homogeneity.

\section{SDF1-3'A Genetic Polymorphism}

The SDF1-3'A allele was genotyped by PCR amplification using the primers $5^{\prime}$-CAGTCAACCTGGGCAAAGCC-3' (sense), and $5^{\prime}$-CCTGAGAGTCCTTTTGCGGG-3' (antisense), and posterior restriction with $M s p$ I endonuclease [18]. In a double-blind manner, we randomly selected $10 \%$ of the participants to reconfirm the genotypes with HpaII endonuclease [19], and obtained the same results.

\section{Statistical Analysis}

Allele frequencies and genotype distribution comparisons between groups and Hardy-Weinberg analysis were performed by $\chi^{2}$ or Fisher's exact test with Definetti software (available at http://ihg. gsf.de/cgi-bin/hw/hwa1.pl). The logistic regression model was used to analyze the association of SDF1-3'A polymorphism with CD4+ T-lymphocyte and viral load categories in patients, and with HIV-1 exposure levels in female sex workers. $\mathrm{p}<0.05$ was considered statistically significant. All analyses were performed with Stata Intercooled version 13.1.

\section{Results}

Genotype analysis did not show any significant deviation from the Hardy-Weinberg expectation in the study groups $(\mathrm{p}=1.00$ in patients, $\mathrm{p}=0.75$ in sex workers, and $\mathrm{p}=0.31$ in healthy blood controls). The allelic and genotypic distribution is shown in table 2. As observed, $14.7 \%$ of the general population are carriers of the SDF1-3'A allele, slightly lower than in HIV-1/AIDS patients $(\mathrm{OR}=$ $1.27, \mathrm{p}=0.18$ ). However, when the patients were categorized by gender we found that in females the A allele and GA genotype frequency are significantly more prevalent and the $\mathrm{G}$ allele significantly more reduced compared to males ( $\mathrm{p}=0.002$ for both alleles, $\mathrm{p}=0.003$ for GA heterozygous genotype). Similar results were observed when comparing the former group to female healthy controls and female sex worker groups.

The genotypes were not associated with CD4+ T cell categories or viral load levels (table 3), neither to the exposition levels to HIV-1 in female sex workers (data not shown). There were no patients with undetectable viral load because the levels were estimated according to the mean of all measures of each patient. Unfortunately, both therapy start date and the number/proportion of treatment failures were not reported. However, the viral load observed in those patients under treatment can be due to the inclusion of values of viral load previous to the treatment in viremic patients. 
Table 2. Allele and genotype frequencies of the SDF1-3'A polymorphism in HIV-infected patients, healthy blood donors, and female sex workers

\begin{tabular}{|c|c|c|c|c|c|c|c|}
\hline \multirow[t]{2}{*}{ Genotypes } & \multicolumn{2}{|l|}{ Male $(n=299)$} & \multicolumn{3}{|c|}{ Female $(\mathrm{n}=335)$} & \multicolumn{2}{|c|}{$\operatorname{Total}^{1}(\mathrm{n}=460)$} \\
\hline & $\begin{array}{l}\text { patients } \\
(\mathrm{n}=139)\end{array}$ & $\begin{array}{l}\text { healthy BD } \\
(\mathrm{n}=160)\end{array}$ & $\begin{array}{l}\text { patients } \\
(\mathrm{n}=65)\end{array}$ & $\begin{array}{l}\text { healthy BD } \\
(\mathrm{n}=96)\end{array}$ & $\begin{array}{l}\text { sex workers } \\
(\mathrm{n}=174)\end{array}$ & $\begin{array}{l}\text { patients } \\
(\mathrm{n}=204)\end{array}$ & $\begin{array}{l}\text { healthy BD } \\
(n=256)\end{array}$ \\
\hline GG, n (\%) & $103(74.10)$ & $113(70.62)$ & $34(52.30)$ & $71(73.95)$ & $129(74.13)$ & $137(67.15)$ & $184(71.87)$ \\
\hline GA, n (\%) & $33(23.74)^{\mathrm{c}}$ & $45(28.12)$ & $28(43.07)$ & $24(25.00)^{\mathrm{f}}$ & $41(23.36)^{\mathrm{i}}$ & $61(29.90)$ & $69(26.95)$ \\
\hline $\mathrm{AA}, \mathrm{n}(\%)$ & $3(2.16)$ & $2(1.25)$ & $3(4.61)$ & $1(1.04)$ & $4(2.29)$ & $6(2.94)$ & $3(1.17)$ \\
\hline G allele, \% & $85.97^{\mathrm{a}}$ & 84.68 & 73.8 & $86.45^{\mathrm{d}}$ & $85.92^{\mathrm{g}}$ & 82.11 & 85.35 \\
\hline A allele, $\%$ & $14.03^{\mathrm{b}}$ & 15.32 & 26.2 & $13.55^{\mathrm{e}}$ & $14.08^{\mathrm{h}}$ & 17.89 & 14.65 \\
\hline
\end{tabular}

$\mathrm{BD}=$ Blood donors. Male patients vs. female patients: ${ }^{\mathrm{a}, \mathrm{b}} \mathrm{p}=0.002$ for both $\mathrm{G}$ and A alleles. ${ }^{\mathrm{c}} \mathrm{p}=0.003$ for GA heterozygous genotype. Female healthy BD vs. female patients: ${ }^{\mathrm{d}} \mathrm{p}=0.004, \mathrm{OR}=0.44$ (95\% CI: $\left.0.25-0.78\right)$ for the G allele. ${ }^{\mathrm{e}} \mathrm{p}=0.004, \mathrm{OR}=2.26(95 \% \mathrm{CI}$ : $1.28-3.99)$ for the A allele. ${ }^{\mathrm{f}} \mathrm{p}=0.009, \mathrm{OR}=2.43$ (95\% CI: $\left.1.23-4.81\right)$ for the GA genotype. Female sex workers vs. female patients: ${ }^{\mathrm{g}} \mathrm{p}=0.001, \mathrm{OR}=0.46$ (95\% CI: $\left.0.282-0.758\right)$ for the $\mathrm{G}$ allele. ${ }^{\mathrm{h}} \mathrm{p}=0.001, \mathrm{OR}=2.16(95 \% \mathrm{CI}: 1.31-3.54)$ for the A allele. ${ }^{\mathrm{i}} \mathrm{p}=0.001, \mathrm{OR}=$ 2.59 (95\% CI: $1.40-4.77)$ for the GA heterozygous genotype. ${ }^{1}$ This total does not include female sex workers.

Table 3. Correlation of SDF1-3'A genotypes with CD4+ T-lymphocyte categories and viral load levels

\begin{tabular}{|c|c|c|c|c|c|c|c|c|c|}
\hline \multirow[t]{2}{*}{ Variables } & \multicolumn{9}{|c|}{ Genotype frequency } \\
\hline & \multicolumn{3}{|l|}{ SDF1 $w t / w t$} & \multicolumn{3}{|c|}{$\mathrm{SDF} 1 w t / 3^{\prime} \mathrm{A}$} & \multicolumn{3}{|c|}{ SDF $1-3^{\prime} \mathrm{A} / 3^{\prime} \mathrm{A}$} \\
\hline \multicolumn{10}{|c|}{ CD4+ T-cell categories } \\
\hline & 1 & 2 & 3 & 1 & 2 & 3 & 1 & 2 & 3 \\
\hline & $53(38.7)$ & $68(49.6)$ & $16(11.7)$ & $29(47.54)$ & $30(49.18)$ & $2(3.28)$ & $3(50)$ & $1(16.67)$ & $2(33.33)$ \\
\hline \multicolumn{10}{|c|}{ Plasma HIV-1 RNA levels ${ }^{1}$} \\
\hline & low & middle & high & low & middle & high & low & middle & high \\
\hline & $73(53.28)$ & $56(40.88)$ & $8(5.84)$ & $29(47.54)$ & $30(49.18)$ & $2(3.28)$ & $3(50)$ & $2(33.33)$ & $1(16.67)$ \\
\hline Total $(\mathrm{n}=204)$ & $137(67.16)$ & & & $61(29.90)$ & & & $6(2.94$ & & \\
\hline
\end{tabular}

Values are given as $\mathrm{n}(\%) . \mathrm{wt} / \mathrm{wt}=$ Homozygous wild-type allele; $\mathrm{wt} / 3^{\prime} \mathrm{A}=$ heterozygous; $3^{\prime} \mathrm{A} / 3^{\prime} \mathrm{A}=$ homozygous for $3^{\prime} \mathrm{A}$ allele. $\mathrm{p}$ was not significant for any comparison $(\mathrm{p}>0.05) .{ }^{1}$ The plasma HIV-1 RNA levels were defined as low $(<400$ copies/ml or undetectable), middle $(400-100,000 / \mathrm{ml})$, and high $(>100,000$ copies $/ \mathrm{ml})$, and represent the mean of all estimations of each patient. Low or undetectable means that the assay was not sensitive enough to detect virus, not that HIV is not present.

\section{Discussion}

This study describes the genotypes and allele frequencies of the SDF1-3'A polymorphism in both HIV-1-infected and uninfected individuals from Northwest Mexico and their effects on surrogate markers (HIV-1 RNA levels in plasma and CD4 + T-cell counts) as indicators of HIV-disease progression.

SDF-1 is the chemokine ligand of CXCR4 and restricts HIV-1 infection, particularly by T-tropic virions mainly in the AIDS phase [6]. The polymorphism located at the $3^{\prime}$ untranslated region (SDF1-3'A or rs1801157) seems to involve upregulation of the quantity of SDF-1 protein available, and thus delays disease progression in HIV1 -infected individuals $[9,17]$. Nevertheless, our results were opposed because we found a possible effect in the susceptibility in females; however, this is in agreement with the observation by Wang et al. [13] in that the SDF1$3^{\prime} \mathrm{A}$ allele is associated with a high risk of HIV-1 infection by sexual transmission in Han Chinese. In fact, in our cohort, $98 \%$ of the patients acquired the infection through sexual transmission.

Even though no statistically significant differences were observed in the frequencies of alleles and genotypes 
in the studied groups, when the analysis was stratified by gender it revealed a significantly decreased frequency of the $G$ allele and an increase of the A allele and GA genotype in female patients compared to male patients, as well as other group of females, suggesting that the $G$ allele may be associated with protection, while the A allele and GA genotype might be associated with susceptibility to HIV-1 infection only among females. Additionally, in females with category 1 of $\mathrm{CD} 4+$, the GG genotype was found in 53 versus $48.4 \%$ with the GA + AA genotype, compared to 34 versus $47 \%$ in males with category 1 , respectively; however, in female and male patients with a low level of HIV1 RNA copies, the same genotypes were found in 56 versus $51.6 \%$, and 52.4 versus $47 \%$, respectively. A similar finding was reported by Brambilla et al. [14], who found a correlation of AA homozygotes with both death and loss of CD4+ T cell counts to below 200 (relative hazard of 2.16 and 3.43 , respectively) compared to GG and GA genotypes, although no changes on viral load were observed. Unfortunately, gender-stratified analyses were not made.

In spite of the tendency observed in the GG genotype toward the protection against of progression of HIV-1 infection, the CD4+ T-lymphocyte categories and plasma viral RNA levels did not differ significantly in those patients with and without the SDF1-3'A polymorphism, which could be because almost all patients were under antiretroviral therapy or because the genotype AA in our population has a low frequency ( $1.1 \%$ in general population vs. $3 \%$ in patients) - lower than that reported by Winkler et al. [9] in a white population (4-5\%). Our results agree with the findings of Lathey et al. [20] in that SDF1-3'A genotype has no effect on HIV-1 load or CD4+ cell counts of patients under antiretroviral therapy.

There are many reports about SDF1-3'A on susceptibility or protection to several diseases, but its association in HIV-1-infected women has not been reported. This gender-specific system of immune responses has been observed for HIV-1 infection for several years and there is evidence of it. For example, the viral load is $40 \%$ decreased in females [21], but when females and males possess the same viral loads, the infection progresses faster to AIDS in females $[22,23]$. Also, some genetic variants show differences in their frequency when the patients are sex-stratified. Philpott et al. [24], and then Estrada-Aguirre et al. [25], reported a protective effect of the CCR5 Delta-32 allele against HIV-1 infection in females, which is assumed to be the most important genetic factor in the natural resistance to $\mathrm{HIV}-1$ infection [26]. Moreover, $\mathrm{Hu}$ et al. [27] recently reported the A/G genotype and $G$ allele at promoter region of IL22 gene to be a protective factor only in females. However, Selvaraj et al. [28] found a significant increase in the frequency of the GG genotype and a significant decrease in the GA genotype in female patients with pulmonary tuberculosis, pointing to the role of sex hormones on the capacity of regulating expression of CCR5 and CXCR4 receptors [29]. Nevertheless, more studies on susceptibility to infectious and noninfectious diseases in women of all populations are required to explain the differential behavior of hormones within the binomial health disease.

It would be interesting to know the distribution of SDF1-3'A genotypes and their possible effects according to type of exposure, i.e. sexual (vaginal or anal intercourse) or intravenous drug use. Unfortunately, there are few women in the current study, and of these only one was an intravenous drug user. It is also difficult to know whether infection in sexual transmission cases occurred through vaginal or anal intercourse. Another limitation was not to quantify the plasma SDF-1 levels and their association with SDF1-3'A genotypes and HIV-1 RNA levels and CD4+ T-cell counts as indicators of progression. However, several studies have shown contrasting results $[13,30]$ and therefore no consensus exists about a true relationship between these parameters.

Furthermore, there are nonsyncytium-inducing and syncytium-inducing HIV-1 strains that use the CCR5 and CXCR4 receptors for cell entry, respectively [6]. It has been postulated that CCR5 is from newly infected individuals, that CXCR4 appears much later after the primary infection, and that homozygosity for Delta-32-bp deletion in the CCR5 allele prevents cellular entry of CCR5tropic HIV type 1 strains [31]. The existence of HIV1-infected patients homozygous for the Delta-32 allele $[32,33]$ means that there are other coreceptors contributing to virus entry, like CXCR4, CCR1, CCR8, CCR2, and CCR3B [19, 34, 35], despite the lack of CCR5. For this reason, at least in part, several studies have failed to correlate the SDF1-3'A genotype to coreceptor usage $[14,20$, 36].

Our findings, along with previous data, show that the SDF1-3'A polymorphism can display multiple effects on HIV-1/AIDS pathogenesis, depending on the studied population. Therefore, we cannot assure, but neither discard, the SDF1-3'A polymorphism as a genetic marker for progression to AIDS, at least in the studied population. A large cohort of HIV-1-infected naive patients (including females and males) carriers of both AA and GA + GG genotypes and monitoring their possible progression to AIDS would be suitable to further evaluate the significance of our findings. 


\section{Acknowledgements}

\section{References}

1 https://www.aids.gov/hiv-aids-basics/hivaids-101/global-statistics/ (accessed on March 9, 2015).

2 CENSIDA/Secretaría de Salud 2012, El VIH/ SIDA en México 2012.

3 Rowland-Jones SL, Pinheiro S, Kaul R, Hansasuta P, Gillespie G, Dong T, et al: How important is the 'quality' of the cytotoxic T lymphocyte (CTL) response in protection against HIV infection? Immunol Lett 2001;79:15-20.

4 O'Brien SJ, Nelson GW: Human genes that limit AIDS. Nat Genet 2004;36:565-574.

5 Doranz BJ, Rucker J, Yi Y, Smyth RJ, Samson M, Peiper SC, et al: A dual tropic isolate that uses fusin and the beta chemokine receptors CKR-5, CKR-3, and CKR-2b as fusion cofactors. Cell 1996;85:1149-1158.

6 Arenzana-Seisdedos F: SDF-1/CXCL12: a chemokine in the life cycle of HIV. Front Immunol 2015;6:256.

7 Karin N: The multiple faces of CXCL12 (SDF$1 a)$ in the regulation of immunity during health and disease. J Leukoc Biol 2010;88: 463-473.

8 Alkhatib G: The biology of CCR5 and CXCR4. Curr Opin HIV AIDS 2009;4:96-103.

9 Winkler C, Modi W, Smith MW, Nelson GW, Wu X, Carrington M: Genetic restriction of AIDS pathogenesis by an SDF-1 chemokine gene variant. Science 1998;279:389-393.

10 Tiensiwakul P: Stromal cell-derived factor (SDF) 1-3'A polymorphism may play a role in resistance to HIV-1 infection in seronegative high-risk Thais. Intervirology 2004;47:87-92.

11 Reiche EM, Ehara Watanabe MA, Bonametti AM, Kaminami Morimoto H, Akira Morimoto A, Wiechmann SL, et al: The effect of stromal cell-derived factor 1 (SDF1/CXCL12) genetic polymorphism on HIV-1 disease progression. Int J Mol Med 2006; 18:785-793.

12 Mahajan SD, Agosto-Mojica A, Aalinkeel R, Reynolds JL, Nair BB, Sykes DE, et al: Role of chemokine and cytokine polymorphisms in the progression of HIV-1 disease. Biochem Biophys Res Commun 2010;396:348-352.

13 Wang Y, Wang X, Peng J, Chen L, Cheng J, Nie S, et al: SDF1-3'A gene mutation is correlated with increased susceptibility to HIV type 1 infection by sexual transmission in Han Chinese. AIDS Res Hum Retroviruses 2008; 24:1341-1345.

14 Brambilla A, Villa C, Rissardi G: Shorter survival of SDF1-3 A/3A homozygotes linked to $\mathrm{CD} 4 \mathrm{~T}$ cell decrease in advanced human immunodeficiency virus type 1 infection. J Infect Dis 2000;182:311-315.

15 Petersen DC, Glashoff RH, Shrestha S, Bergeron J, Laten A, Gold B, et al: Risk for
We are grateful to PROMEP 2012 (NPTC-PROMEP/2012-103.5/12/3360 grant), Dr. Raul Borrego Gaxiola for constant support at Hospital General de Culiacán 'Bernardo J. Gastélum', and especially to participating subjects.
HIV-1 infection associated with a common CXCL12 (SDF1) polymorphism and CXCR4 variation in an African population. Acquir Immune Defic Syndr 2005;40:521-526.

16 Amara S, Domenech J, Jenhani F: Stromal cell-derived factor 1 polymorphism in patients infected with HIV and implications for AIDS progression in Tunisia. HIV AIDS 2010;2:203-209.

17 Liu S, Zhu H: Association between polymorphism of SDF1 (CXCL12) gene and HIV-1 susceptibility: a meta-analysis. Curr HIV Res 2011;9:112-119.

18 Juhász E, Béres J, Kanizsai S, Nagy K: The consequence of a founder effect: CCR5- $\triangle 32$, CCR2-64I and SDF1-3'A polymorphism in Vlach Gypsy population in Hungary. Pathol Oncol Res 2012;18:177-182.

19 Qian Y, Sun H, Lin K, Shi L, Shi L, Chu J: Distribution of CCR5- $\triangle 32$, CCR2-64I, SDF1$3^{\prime} \mathrm{A}, \mathrm{CX} 3 \mathrm{CR} 1-249 \mathrm{I}$, and CX3CR1-280M in Chinese populations. AIDS Res Hum Retroviruses 2008;24:1391-1397.

20 Lathey JL, Tierney C, Chang SY, D'Aquila RT, Bettendorf DM, Alexander HC, et al: Associations of CCR5, CCR2, and stromal cell-derived factor 1 genotypes with human immunodeficiency virus disease progression in patients receiving nucleoside therapy. J Infect Dis 2001;184:1402-1411.

21 Sterling TR, Vlahov D, Astemborski J, Hoover DR, Margolick JB, Quinn TC: Initial plasma HIV-1 RNA levels and progression to AIDS in women and men. N Engl J Med 2001;344 720-725.

22 Farzadegan H, Hoover DR, Astemborski J, Lyles CM, Margolick JB, Markham RB, et al: Sex differences in HIV-1 viral load and progression to AIDS. Lancet 1998;352:1510-1514.

23 Meier A, Chang JJ, Chan ES, Pollard RB, Sidhu HK, Kulkarni S, et al: Sex differences in the Toll-like receptor-mediated response of plasmacytoid dendritic cells to HIV-1. Nat Med 2009;15:955-959.

24 Philpott S, Weiser B, Tarwater P, Vermund $\mathrm{SH}$, Kleeberger CA, Gange SJ, et al: Chemokine receptor 5 genotype and susceptibility to transmission of human immunodeficiency virus type 1 in women. J Infect Dis 2003;187: 569-575.

25 Estrada-Aguirre JA, Cázarez-Salazar SG, Ochoa-Ramírez LA, Acosta-Cota Sde J, Zamora-Gómez R, Najar-Reyes GM, et al: Protective effect of CCR5 Delta-32 allele against HIV-1 in Mexican women. Curr HIV Res 2013:11;506-510.

26 Smith MW, Dean M, Carrington M, Winkler C, Huttley GA, Lomb DA, et al: Contrasting genetic influence of CCR 2 and CCR 5 variants on HIV-1 infection and disease progression. Hemophilia Growth and Development Study (HGDS), Multicenter AIDS Cohort Study (MACS), Multicenter Hemophilia Cohort Study (MHCS), San Francisco City Cohort (SFCC), ALIVE Study. Science 1997;277:959965.

$27 \mathrm{Hu}$ J, Li Y, Chen L, Yang Z, Zhao G, Wang Y, et al: Impact of IL-22 gene polymorphism on human immunodeficiency virus infection in Han Chinese patients. J Microbiol Immunol Infect 2014, pii: S1684-1182(14)00226-6.

28 Selvaraj P, Alagarasu K, Singh B: Stromal cellderived factor-1 (SDF-1/CXCL12) gene polymorphisms in pulmonary tuberculosis patients of South India. Int J Immunogenet 2012;39:26-31.

29 Vassiliadou N, Tucker L, Anderson DJ: Progesterone-induced inhibition of chemokine receptor expression on peripheral blood mononuclear cells correlates with reduced HIV-1 infectability in vitro. J Immunol 1999; 162:7510-7518.

30 Soriano A, Martínez C, García F, Plana M Palou E, Lejeune M, et al: Plasma stromal cellderived factor (SDF)-1 levels, SDF1-3'A genotype, and expression of CXCR4 on T lymphocytes: their impact on resistance to human immunodeficiency virus type 1 infection and its progression. J Infect Dis 2002;186:922931

31 De Clercq E, Schols D: Inhibition of HIV infection by CXCR 4 and CCR 5 chemokine receptor antagonists. Antivir Chem Chemother 2001;12:19-31.

32 Balotta C, Bagnarelli P, Violin M, Ridolfo AL, Zhou D, Berlusconi A, et al: Homozygous delta 32 deletion of the CCR- 5 chemokine receptor gene in an HIV-1-infected patient. AIDS 1997;11:F67-F71.

33 Hütter G: More on shift of HIV tropism in stem-cell transplantation with CCR5 delta32/ delta32 mutation. N Engl J Med 2014;371: 2437-2438.

34 Kostrikis LG, Huang Y, Moore JP, Wolinsky SM, Zhang L, Guo Y, et al: A chemokine receptor CCR2 allele delays HIV-1 disease progression and is associated with a CCR5 promoter mutation. Nat Med 1998;4:350353.

35 Shioda T, Nakayama EE: Human genetic polymorphism affecting HIV-1 diseases. Int J Hematol 2006;84:12-17.

36 Van Rij RP, Broersen S, Goudsmit J: The role of a stromal cell-derived factor-1 chemokine gene variant in the clinical course of HIV-1 infection. AIDS 1998;12:F85-F90. 